\title{
The STEM Gender Gap: an Evaluation of the Efficacy of Women in Engi- neering Camps
}

\section{Malle Schilling, University of Dayton}

Malle Schilling is a senior mechanical engineering student at the University of Dayton. This paper is a result of work done to complete her honors thesis through the University Honors Program. She is interested in engineering education, diversity in engineering, outreach and policy.

\section{Dr. Margaret Pinnell, University of Dayton}

Dr. Margaret Pinnell is the Associate Dean for Faculty and Staff Development in the school of engineering and associate professor in the Department of Mechanical and Aerospace Engineering at the University of Dayton. She teaches undergraduate and graduate materials related courses including Introduction to Materials, Materials Laboratory, Engineering Innovation, Biomaterials and Engineering Design and Appropriate Technology (ETHOS). She was director of the (Engineers in Technical Humanitarian Opportunities of Service-Learning) for approximately ten years. She has incorporated service-learning projects into her classes and laboratories since she started teaching in 2000. Her research interests include community engaged learning and pedagogy, K-12 outreach, biomaterials and materials testing and analysis. 


\title{
The STEM Gender Gap: An Evaluation of the Efficacy of Women in Engineering Camps
}

\author{
Author Name(s) Malle Schilling and Dr. Margaret Pinnell \\ School of Engineering \\ University of Dayton \\ Dayton, Ohio 45469 \\ Email: schillingm3@udayton.edu
}

\begin{abstract}
In the present day, it is not uncommon for there to be a class full of engineering students with very few women in the room. To combat this lack of gender diversity, colleges and universities have employed outreach programs and developed summer engagement opportunities that allow women to explore engineering before they graduate high school. As these programs grow, there is a need to explore how they are affect the women who participate in them. A research study was conducted to evaluate if two different week-long, residential engineering camps at the University of Dayton had a positive influence on participants' perception of and interest in engineering. One camp was a single-sex female camp and the other was a co-ed camp. Data was collected through observation and surveys. The surveys were used to collect quantitative data from consenting participants $(\mathrm{n}=112)$. The results of the survey indicated that the femaleidentified participants from the single-sex camp $(\mathrm{n}=54)$ were positively affected by their camp experience. The change from pre-camp to post-camp responses showed a significant positive increase of the average response in how participants viewed engineering $(\Delta \bar{x}=0.26, \mathrm{p}=0.01)$, and their self-efficacy regarding becoming an engineer $(\Delta \bar{x}=0.22, \mathrm{p}=0.04)$. In contrast, the results of female participants at the co-ed camp indicated that the average response regarding how they viewed engineering did not increase to the same degree $(\Delta \bar{x}=0.06)$, and their self-efficacy towards becoming an engineer decreased $(\Delta \bar{x}=-0.24)$. Though notable, this decrease showed no statistical significance due to the small sample size of female-identified participants at the co-ed camp $(n=17)$. A comparison of the responses from female-identified and male-identified participants also supports existing research that demonstrates women having a weaker identification with math than men. These results suggest two things: a co-ed camp model may not be the ideal model for fostering women's interest in engineering, and a single-sex camp model can have positive effects on the women who attend and participate.
\end{abstract}

\section{Introduction}

During World War II, manufacturing companies such as GE and Curtiss-Wright began to hire women to function as engineers when the men left to fight in the war [1], [2]. Although the women were not formally trained as engineers, many were hired in engineering roles to ensure that the manufacturing companies could produce aircraft parts needed to support the war. When the war ended and the men began returning to their manufacturing jobs, women's place in the engineering workplace became obsolete. However, women who worked in manufacturing companies during the war helped to break the barrier of female participation in engineering. Though there were a few engineering programs at schools such as Cornell and MIT open to women prior to World War II, more programs began to open their doors to women. In 1945, out of the 48,977 students enrolled in engineering courses, nearly $3.5 \%(1,801)$ were women [2]. Although the total number of women in engineering has increased since 1945, the field of 
engineering continues to lack female representation despite the fact that, in 2008, women represented 56.38\% of enrolled students at public universities [3]. In 2013 only $1.6 \%$ of collegeenrolled women graduated with degrees in science and engineering compared to $8.9 \%$ of collegeenrolled men [4]. In 2017, 28\% of Miami University's incoming class of engineering students was female while $20 \%$ of the University of Cincinnati's class was female [5]. A similar gender gap is seen in the employment of women in engineering fields; for example, women only represented $15.4 \%$ of employees in architecture and engineering occupations as of 2014 [6]. This persistent gender disparity begs the following question: why do women not choose to pursue engineering?

There are several factors that are important to consider when trying to understand why females do not choose to pursue engineering. First, career choice is not an objective measure of ability, nor are gender differences in course choices and career aspirations in science, technology, engineering, and math (STEM) a function of objectively measured math competencies. Second, students are more likely to select math and science courses when they are confident in their ability to do well in these courses. In other words, students with greater self-efficacy in science and math are more likely to choose these courses. Third, the value a student places on particular school subjects are important for their career trajectory. Finally, the perception of strong social support for achievement is vital when a student is considering a career choice, which is particularly true for females [7].

Through the use of implicit and self-report measure, it was found that elementary school females supported the stereotype that math is for males, demonstrating that elementary school girls experience a weaker identification with math than boys [8]. Evidence has also been found supporting the idea that stereotype endorsement (i.e., a math-gender stereotype), has an effect on "women's disengagement from math and science" [9]. This is supported by another study that demonstrated gender stereotyping had a negative impact on the math performance for female students. Further, the more these students held onto the math-gender stereotype, the lower their math performance [10]. The pervasiveness of this stereotype in our society has resulted in many females feeling as though they do not have the ability to succeed in science and math. According to Frontier and Rickabaugh, "the presence or absence of strong self-efficacy often determines whether learners will engage in challenging tasks in which the outcome of the work is not certain" [11]. Therefore, a key reason that women may not be pursuing STEM fields is that they lack self-efficacy in science and math, and do not have the resources to support them.

Research suggests that there is also close link between a child's early interest in science and family influence [12], [13]. If peers, teachers and parents do not believe women should go in to STEM and they do not foster an interest in STEM at an early age, a female child may also believe she does not belong in STEM. However, opportunities and other resources should be made available to counteract the effects of the gendered stereotypes [14].

To encourage females to consider engineering as a career field, many colleges and universities, such as Ohio State University, Akron University, Arizona State University, and Purdue University, have developed various outreach and summer engagement opportunities to provide young women with the opportunity to explore engineering before graduating from high school [15], [16], [17], [18]. Engineering camps are often marketed toward specific minorities, such as 
women, or they are offered as co-ed. During engineering camps, participants engage in many activities related to various fields of engineering. These activities are meant to provide some context for what engineering is, what engineers do, and what it takes to become an engineer. When participants attend these camps, it is an opportunity for them to build their engineering self-efficacy. This is especially important for women, who are often under the impression that they cannot be engineers. Engineering camps can provide women the tools to build their selfefficacy and allow them to discover that they can succeed in engineering [19].

Although these engineering camps have been in existence for at least 20 years, only recently have efforts been taken to examine the efficacy of the camps at helping to increase the camp participant's interest and self-efficacy in engineering [20]. However, it is necessary to examine engineering camps to understand the effects they have on their participants: are these camps turning participants away from engineering or are they building confidence and a desire to continue with engineering?

The purpose of this study was to evaluate the effects of single-sex female and co-ed engineering camps at the University of Dayton on female participants' interest in engineering and their selfefficacy related to engineering.

\section{Method}

In an effort to assess the efficacy of both co-ed and single-sex female engineering summer camps at increasing the participants interest in and self-efficacy in engineering, both qualitative and quantitative data were collected from each type of engineering camp. Each camp took place over a period of six days and featured activities that allowed participants to explore various engineering fields. It should be noted that the camp activities varied between the single-sex female and co-ed camps; different facilitators were present and facilitated different activities within the same field of engineering. The participants in attendance were high school students from across the United States. A total of 112 participants consented to participating in this study.

Quantitative data was collected from disseminated paper pre-camp and post-camp surveys. The pre-camp survey was disseminated to participants during the orientation session prior to any camp activity. The post-camp survey was disseminated at the closing session after the end of all camp activities. Participants were asked to create an identification code to link their pre-camp and post-camp surveys. Surveys that were not able to be linked were excluded from the data analysis. This study was given approval by an institutional review board.

The surveys allowed participants to self-report their willingness to problem solve, their persistence when faced with a challenge, their self-assertiveness, their self-efficacy in math, science, and engineering, and their interest in and intention to pursue engineering (Appendix A) [21]. Additionally, some questions were modified from the Assessing Women and Men in Engineering (AWE) project surveys to make them more relevant to high school age participants [22]. For example, terms such as "engineering curriculum" were changed to "math and science courses" because it would be better understood by the participant population. Other questions were also tailored to the participant population under the assumption that not all participants were of an age where they would be deciding what major to pursue in college. Therefore, one 
question gauges interest in engineering as a college major while another gauges intention to pursue engineering. Questions were also influenced by research conducted on how engineering is viewed [23].

A total of 112 responses from consenting participants were analyzed in three groups: one group of the female participants from the single-sex engineering camp $(n=54)$, one group of the male participants from the co-ed engineering camp $(n=41)$, and one group of the female participants from the co-ed engineering camp $(n=17)$. Pre-camp and post-camp survey responses were separated by group. Responses to set-response were analyzed using a paired t-test to determine any significant differences between the pre-camp and post-camp responses. By determining significance and shifts in the average responses, the effects of the camp on the participant's interest in and self-efficacy in engineering were able to be identified. Responses to open-ended questions were coded for how often the responses occurred.

Qualitative data was collected in the form of observation of camp activities to provide context for the survey responses. It should be noted that not all activities between the camps were identical.

\section{Results}

Group 1 refers to the female participants who attended the single-sex, Group 2 refers to the male participants who attended the co-ed camp, and Group 3 refers to the female participants who attended the co-ed camp. Table 1 shows the results for each set-response question.

Table 1: Average Response of Participants

\begin{tabular}{|c|c|c|c|c|c|c|c|c|c|c|}
\hline $\begin{array}{c}\text { Question } \\
\text { (Scale) }\end{array}$ & $\begin{array}{c}\text { Q1 } \\
(1-5)\end{array}$ & $\begin{array}{c}\text { Q2 } \\
(1-5)\end{array}$ & $\begin{array}{c}\text { Q3 } \\
(1-4)\end{array}$ & $\begin{array}{c}\text { Q4 } \\
(1-5)\end{array}$ & $\begin{array}{c}\text { Q5 } \\
(1-5)\end{array}$ & $\begin{array}{c}\text { Q7 } \\
(1-4)\end{array}$ & $\begin{array}{c}\text { Q8 } \\
(1-5)\end{array}$ & $\begin{array}{c}\text { Q9 } \\
(1-5)\end{array}$ & $\begin{array}{l}\text { Q10 } \\
(1-5)\end{array}$ & $\mathbf{n}$ \\
\hline $\begin{array}{r}\text { Group 1 } \\
\text { Pre-camp }\end{array}$ & 4.57 & 4.33 & 2.48 & 4.19 & 4.61 & 3.63 & 4.46 & 4.24 & 3.91 & \multirow{3}{*}{54} \\
\hline $\begin{array}{r}\text { Group } 1 \\
\text { Post-camp }\end{array}$ & 4.56 & 4.39 & 2.43 & 4.32 & 4.55 & 3.89 & 4.43 & 4.39 & 4.13 & \\
\hline Difference & -0.01 & 0.06 & -0.05 & 0.13 & -0.06 & $0.26^{* *}$ & -0.03 & 0.15 & $0.22 *$ & \\
\hline $\begin{array}{r}\text { Group } 2 \\
\text { Pre-camp }\end{array}$ & 4.5 & 4.39 & 2.56 & 4.49 & 4.71 & 3.66 & 4.59 & 4.49 & 4.29 & \multirow{3}{*}{41} \\
\hline $\begin{array}{r}\text { Group } 2 \\
\text { Post-camp }\end{array}$ & 4.56 & 4.54 & 2.61 & 4.68 & 4.8 & 3.8 & 4.68 & 4.61 & 4.59 & \\
\hline Difference & 0.06 & $0.15^{* *}$ & 0.05 & $0.19 * *$ & $0.09 *$ & 0.14 & 0.09 & 0.12 & $0.3 * *$ & \\
\hline $\begin{array}{r}\text { Group } 3 \\
\text { Pre-camp }\end{array}$ & 4.53 & 4.47 & 2.29 & 4.06 & 4.65 & 3.65 & 4.65 & 4.59 & 4.35 & \multirow{3}{*}{17} \\
\hline $\begin{array}{r}\text { Group } 3 \\
\text { Post-camp }\end{array}$ & 4.65 & 4.47 & 2.35 & 4.18 & 4.59 & 3.71 & 4.59 & 4.53 & 4.12 & \\
\hline Difference & 0.12 & 0 & 0.06 & 0.12 & -0.06 & 0.06 & -0.06 & -0.06 & -0.23 & \\
\hline
\end{tabular}

*Indicates the difference between the pre-camp and post-camp response showed statistical significance $(\mathrm{p} \leq 0.05)$.

**Indicates the difference between the pre-camp and post-camp response showed statistical significance $(\mathrm{p} \leq 0.01)$. 
For Group 1, questions 7 and 10, which asked participants to identify a statement related to how they view engineering and asked about their self-efficacy related to engineering, respectively, showed statistical significance $(\mathrm{p}=0.01$ and $\mathrm{p}=0.04$, respectively). The average response for these questions increased from pre-camp to post-camp. For Group 2, questions 2, 4, 5, and 10, which asked participants questions about their persistence and self-efficacy related to math, science and engineering, showed statistical significance $(\mathrm{p}=0.01, \mathrm{p}=0.01, \mathrm{p}=0.04$, and $\mathrm{p}=0.002$, respectively). The average responses for these questions increased from pre-camp to post-camp. For Group 3, no questions showed statistical significance. Table 2 shows the distribution of responses for question 10 for all three groups.

Table 2: Distribution of Responses to Question 10 regarding Self-efficacy in Engineering

\begin{tabular}{ccccccc}
\hline \multicolumn{1}{c}{ Response } & $\begin{array}{c}\text { Very } \\
\text { Confident }\end{array}$ & Confident & Neutral & Unconfident & $\begin{array}{c}\text { Very } \\
\text { Unconfident }\end{array}$ \\
\hline Group & Pre-Camp & $20 \%$ & $59 \%$ & $11 \%$ & $9 \%$ & $0 \%$ \\
$\mathbf{1}$ & Post-Camp & $35 \%$ & $52 \%$ & $6 \%$ & $6 \%$ & $2 \%$ \\
\hline Group & Pre-Camp & $32 \%$ & $66 \%$ & $2 \%$ & $0 \%$ & $0 \%$ \\
$\mathbf{2}$ & Post-Camp & $61 \%$ & $37 \%$ & $2 \%$ & $0 \%$ & $0 \%$ \\
\hline Group & Pre-Camp & $47 \%$ & $41 \%$ & $12 \%$ & $0 \%$ & $0 \%$ \\
$\mathbf{3}$ & Post-Camp & $35 \%$ & $47 \%$ & $12 \%$ & $6 \%$ & $0 \%$ \\
\hline
\end{tabular}

Table 3 shows the distribution of responses to Question 6 which asked participants to identify their favorite subjects. The "other" option included responses ranging from band and choir to technology classes in all three groups. The responses in bold will be referenced further in the following discussion session.

Table 3: Distribution of Responses to Question 6 regarding Favorite Subjects

\begin{tabular}{cccccccc}
\hline Subject & Science & Math & $\begin{array}{c}\text { Social } \\
\text { Studies }\end{array}$ & English & Art & $\begin{array}{c}\text { Health/ } \\
\text { Physical } \\
\text { Education }\end{array}$ & Other \\
\hline Group 1 & $65 \%$ & $76 \%$ & $19 \%$ & $17 \%$ & $\mathbf{3 7 \%}$ & $6 \%$ & $13 \%$ \\
\hline Group 2 & $83 \%$ & $71 \%$ & $22 \%$ & $7 \%$ & $5 \%$ & $7 \%$ & $12 \%$ \\
\hline Group 3 & $53 \%$ & $65 \%$ & $12 \%$ & $29 \%$ & $\mathbf{4 7 \%}$ & $0 \%$ & $12 \%$ \\
\hline
\end{tabular}

Tables 4 and 5 show the distribution of responses from the post-camp survey, which asked participants to describe the activity they enjoyed most during camp. The responses in bold will be referenced in the discussion section. 
Table 4: Distribution of Open-Ended Responses to Post-camp Question 11, Group 1, Favorite Camp Activity

\begin{tabular}{cccccc}
\hline Response & $\begin{array}{c}\text { Percent } \\
\text { Response }\end{array}$ & Response & $\begin{array}{c}\text { Percent } \\
\text { Response }\end{array}$ & Response & $\begin{array}{c}\text { Percent } \\
\text { Response }\end{array}$ \\
\hline Chemical Eng. & $\mathbf{2 4 \%}$ & $\begin{array}{c}\text { Hands- } \\
\text { on/engaging } \\
\text { activities }\end{array}$ & $\mathbf{3 0 \%}$ & $\begin{array}{c}\text { Creativity in } \\
\text { Eng. }\end{array}$ & $2 \%$ \\
\hline $\begin{array}{c}\text { Biomedical } \\
\text { Eng. }\end{array}$ & $9 \%$ & $\begin{array}{c}\text { Design } \\
\text { experience }\end{array}$ & $4 \%$ & ETHOS & $6 \%$ \\
\hline $\begin{array}{c}\text { Learn about } \\
\text { diff types of } \\
\text { Eng. }\end{array}$ & $\begin{array}{c}\text { Dinners with } \\
\text { students and } \\
\text { professionals }\end{array}$ & $6 \%$ & $\begin{array}{c}\text { Experiments in } \\
\text { Eng. and } \\
\text { innovation }\end{array}$ & $2 \%$ \\
\hline $\begin{array}{c}\text { Eng. } \\
\text { Technology }\end{array}$ & $\mathbf{4 3 \%}$ & - & - & Industry Tour & $13 \%$ \\
\hline $\begin{array}{c}\text { Mechanical } \\
\text { Eng. }\end{array}$ & $\mathbf{1 7 \%}$ & - & - & - & - \\
\hline \begin{tabular}{l} 
Industrial Eng. \\
\hline
\end{tabular} & $11 \%$ & & - & - \\
\hline
\end{tabular}

Table 5: Distribution of Open-Ended Responses to Post-camp Question 11, Groups 2 and 3, Favorite Camp Activity

\begin{tabular}{|c|c|c|c|c|c|c|c|c|}
\hline Response & Group 2 & Group 3 & Response & Group 2 & Group 3 & Response & Group 2 & Group 3 \\
\hline $\begin{array}{c}\text { Chemical } \\
\text { Eng. }\end{array}$ & $20 \%$ & $18 \%$ & Teamwork & $7 \%$ & $6 \%$ & $\begin{array}{c}\text { Cardboard } \\
\text { table }\end{array}$ & $15 \%$ & $5 \%$ \\
\hline $\begin{array}{l}\text { Wind } \\
\text { tunnel }\end{array}$ & $2 \%$ & $0 \%$ & $\begin{array}{c}\text { Hands-on } \\
\text { activities }\end{array}$ & $10 \%$ & $0 \%$ & $\begin{array}{c}\text { Dinner } \\
\text { with } \\
\text { students } \\
\end{array}$ & $5 \%$ & $0 \%$ \\
\hline $\begin{array}{c}\text { Mechanical } \\
\text { Eng. }\end{array}$ & $12 \%$ & $18 \%$ & Robotics & $22 \%$ & $12 \%$ & $\begin{array}{c}\text { Electrical } \\
\text { Eng. }\end{array}$ & $5 \%$ & $12 \%$ \\
\hline Hot topics & $5 \%$ & $6 \%$ & ETHOS & $5 \%$ & $18 \%$ & $\begin{array}{c}\text { Industrial } \\
\text { Eng. }\end{array}$ & $0 \%$ & $6 \%$ \\
\hline Civil Eng. & $7 \%$ & $6 \%$ & - & - & - & - & - & - \\
\hline
\end{tabular}

\section{Discussion}

Question 10 was shown to have a significant difference in the response between the pre-camp survey and post-camp response for Groups 1 and 2 ( $p=0.04$ and $p=0.002$, respectively). Recalling 
that this question was meant to evaluate the participants' self-efficacy related to becoming an engineer, this significant increase indicates that the single-sex female camp and co-ed camp had a positive effect on the participants in Groups 1 and 2, respectively. The activity that stood out at the single-sex female camp was the engineering technology activity that allowed the participants of Group 1 to build a circuit to create a speaker they could use to play music from their cell phones (Table 4). This activity was well conducted; the facilitator explained the purpose and theory behind why this activity worked, how to perform the required tasks, and then let the participants experience the activity themselves, only intervening to help when needed. As the activity progressed, initial fear-based caution disappeared. The participants were able to correct mistakes as they proceeded and successfully complete the task in the time allotted. According to Shull \& Weiner, activities like this replace "fear-based, undue caution with a sense of appropriate, application-based caution," which is done by placing an emphasis on the process to achieve an outcome, instead of an emphasis on achieving a successful outcome [24]. In this engineering camp, there were many activities that allowed participants to explore engineering, which may have led to an increase in their self-efficacies (Table 2) and a change in how they viewed engineering, demonstrated by the significant increase in the average response of question 7 and 10. The participants learned that engineering can improve lives through solutions that connect science to life, and the thoughts that engineers must be brilliant and do well in math and science, or that engineering only leads to good jobs and making money were shattered.

The significance of the positive difference in responses to questions 2, 4, and 5 for Group 2 should also be noted. Question 2 explores persistence when facing a challenge, and questions 4 and 5 explore confidence in math and science skills and courses, respectively. The increase in the average response to these questions indicates that the co-ed engineering camp had a positive effect on how the male participants viewed challenges and their own math and science abilities. Additionally, the results for questions 4 and 5 indicated that the male participants of Group 2 had a stronger identification with math and science than did the female participants of Groups 1 and 3 (Table 1). This aligns with research that has discovered elementary school girls having a weaker identification with math than boys on both implicit and self-report measures [8].

It should be noted none of these aforementioned results were seen in Group 3's responses. In Group 3, no question reached statistical significance, most likely due to inadequate power. However, the difference between the pre-camp average response and post-camp average response for question 10 showed a decrease, suggesting that these participants had experiences at camp that decreased their self-efficacy related to engineering. To provide further context for this result, it was observed that at the co-ed camp there was a week-long activity that required the participants to design, build, and program a robot to perform certain tasks (Table 5). During the first meeting, the facilitator asked who was familiar with the programming software. The majority of male participants indicated familiarity while the majority of female participants did not. At seeing the large number of participants who had familiarity with the program, the facilitator moved to continue the activity. For the rest of the sessions, the female participants were not actively participating which may have been a result of believing they could not be engineers. Perhaps because they felt they had no experience with this program or activity, they did not believe they have what it takes to be an engineer, which led to the results of Question 10 (Table 2) as well as the low response to the activity in Table 5. It was also noted in other group activities that took place throughout the week, the female participants were often charged with 
taking notes for the group and did not get the opportunity to participate in the various projects due to this responsibility. The activities were well-suited for the male participants who demonstrated greater confidence related to math, science and engineering than their female peers at this camp.

Stereotype threat, (i.e., the pressure or threat a person experiences when a negative stereotype about one's identity group could potentially be confirmed by one's individual performance) may have also had an effect on the female participants of Group 3 [25]. Stereotype threats "can have a negative impact on the performance of targeted individuals" [26]. Because of the possibility of a heightened implicit awareness of stereotypes about women in engineering due to the lack of female participants at the co-ed camp, the female participants were likely affected by the stereotype threat. Their outlook on their own abilities may have been negatively affected, which could account for the decrease in the average response for question 10.

From these results, the difference between Group 1 and Group 3's experiences is apparent. The results from Group 1 demonstrated that they had a positive experience while the results from Group 3 suggest they were negatively affected. Though there is concern about single-sex learning environments furthering stereotypes and elevating gender as the most important factor that affects interest, dispositions, and needs, this was not the case for these female participants [11]. Based on the survey results and observations, the single-sex environment benefitted the female participants more than the co-ed environment. The participants in Group 1 were able to interact with equipment and processes in a way that allowed for them to move beyond fear-based caution and to build confidence. The groups were also observed to be more collaborative as participants offered to help each other and while having relevant and useful discussion during activities. Because there were so few participants in Group 3, the stereotypes thought to pervade single-sex environments were heightened in the co-ed environment. The participants in Group 3 were often not given the same opportunity to collaborate. In fact, it was observed that none of the participants who attended the co-ed camp demonstrated the same levels of collaboration as the single-sex camp, with some groups in the co-ed camp working in almost total silence.

Based on these analyses, there are some suggestions to improve the engineering camp experience for female participants. First, if a co-ed engineering camp model is employed, there should be a 1-to-1 ratio of female-to-male participants. With so few female participants present in a male dominated environment, the potential for stereotype threats to affect the female participants' experience increases. If there is an equal number of female and male participants, the effect of these stereotype threats on the camp experience may not be as great. If this ratio cannot be achieved, it is suggested that an opportunity for females to attend a single-sex camp exist. As this research has demonstrated, this single-sex female camp model had a positive effect on its female participants, while the predominantly male co-ed camp did not. Therefore, it can be argued this model is better suited for fostering female interest and participation in engineering.

Activities at the camps should engage participants. According to Garner, "the more engaged students are in creating meaning, the more they change and learn" [27]. If the participants cannot engage with or create meaning in activities, then their interest in continuing to explore and learn about engineering will decrease. These activities should foster a participant's curiosity and critical thinking skills all while they engage in scientific inquiry through hands-on problem- 
based learning [28]. Problem-based learning is the organization of curriculum around a problem as opposed to a content area that uses methods such as small groups, tutorial instruction, and participant engagement, and has been said to improve motivation towards learning and selfdirected learning, allowing participants to create meaning for themselves in what they do [29], [30]. It is not enough to simply have activities where participants follow step-by-step directions. Participants must be able to experience problems they could encounter as engineers and they must be able to problem-solve and create their own meaningful experiences. One thing that could be incorporated in activities is the entrepreneurial mindset, a term often used by Kern Engineering Entrepreneurial Network (KEEN). This mindset is meant to inspire progress and learning in engineering with the three cornerstones being curiosity, connection, and value. KEEN often emphasizes the importance of being curious about innovative solutions in the changing world, creating connections between what is known and what is learned, and creating value by persisting through and learning from failure [31]. These three principles can be easily integrated into a real world, problem-based learning engineering camp activity. For example, the mechanical engineering activity at the single-sex female camp, which was in the top five favorite activities of Group 1 (Table 4), used the principles of KEEN to engage the participants in identifying a problem, designing a solution, and prototyping a product using unconventional items. The participants had to identify the problem their customer was having and present their solution in brief client presentations. This activity allowed participants to create their own value while they were also learning about engineering and entrepreneurship.

Another way to engage participants is to implement activities that engage their interests. As seen in Table 3, many participants enjoy math and science. However, the female participants in Groups 1 and 3 expressed that they also enjoy art. Incorporating activities that allow participants to use their artistic skills may also allow them the opportunity to connect something they already know they enjoy to something they are learning about; in this case, connecting art to engineering. This connection is especially important to consider when trying to gear an engineering camp toward underrepresented groups. According to Wulf, creativity and art are related to creating diversity in engineering, as it not only attracts people to engineering, but it changes the perspective of what engineering is [32].

The most popular activities were activities that gave participants a hands-on experience and allowed them explore engineering in new ways (Tables 4 through 6). For example, the chemical engineering activity Group 1 participated in allowed them to experience four different chemical engineering activities, demonstrating the range of chemical engineering. The mechanical engineering activities also allowed participants to experience the design process through the design of either a consumer product or a car that was meant to carry a load up an incline. Ultimately, understanding the learning and engagement process, as well as the interests of participants are important factors to creating activities that will positively influence their decisions to pursue engineering.

Limitations of this study include the number of female participants attending the co-ed engineering camp, the difference in camp program, the space in which the surveys were given, and the timing of activities. Though the lack of female participants attending the co-ed camp is representative of the field of engineering, the small sample size did not allow for adequate analytical power; while the data collected from Group 3 was true for Group 3, it is not 
representative of the larger population. In future studies, this survey should be given at a co-ed engineering camp with a more equal ratio of female-to-male participants. Another improvement would be for future research to be conducted at a single-sex camp and co-ed camp that had identical activities. This would allow for consistency between responses given for the post-camp question 11 (participants' favorite activity), and would allow for better analysis of responses. Additionally, the space in which the surveys were given was not structured. Ideally, the participants would be able to sit at desks or tables in a quiet environment while they completed surveys. Lastly, the timing of certain activities and conflicting schedules made it difficult to observe all of the activities that were occurring. It would be worth having a team of researchers observe camp and record activities to provide complete context for the structure of the camp.

\section{Conclusion}

The results of this research suggest two things. First, a single-sex engineering camp model can have positive effects on the self-efficacy of the young women who attend and participate. The co-ed camp model has similar effects on the male participants. However, a co-ed camp model may not be the ideal model for fostering women's interest in engineering. This understanding is important when planning engagement opportunities, especially those engagement opportunities that are marketed to women and other minorities in engineering. Planning activities with real world applications and stories as well as activities that encourage participants to use art are two suggestions for future programming. A better understanding of how all engineering camps affect the self-efficacy of the participants is necessary to understand how to effectively engage them in engineering. 


\section{References}

[1] A.S. Bix, "From 'engineeresses' to 'girl engineers' to 'good engineers': A history of women's U.S. engineering education,” NWSA Journal, vol. 16, no. 1, pp. 27-49, 2004.

[2] A.S. Bix, Girls coming to tech!: A history of American engineering education for women. Cambridge, MA: The MIT Press, 2013.

[3] D. Borzelleca, "The male-female ratio in college," forbes.com, para 4, Feb. 16, 2012. [Online]. Available: https://www.forbes.com/sites/ccap/2012/02/16/the-male-femaleratio-in-college/\#595edb1fa52d. [Accessed Jan. 23, 2018].

[4] National Science Board, "Science and Engineering Indicators 2016," nsf.gov, Jan., 2016. [Online] Available: https://www.nsf.gov/statistics/2016/nsb20161/\#/. [Accessed March 1, 2017].

[5] K. Driscoll and M. Filby, (2017). "College employers want female engineers: Where are they?," Dayton Daily News, para. 2, Aug. 28, 2017. [Online] Available: http://www.daytondailynews.com/business/colleges-employers-want-female-engineerswhere-are-they/iZrpm19aqF16NurkcF2L9L/. [Accessed Jan. 26, 2018].

[6] U.S. Bureau of Labor Statistics (2015). "Women in the labor force: A databook," bls.gov, Dec. 9, 2016. [Online]. Available: https://www.bls.gov/opub/reports/womensdatabook/archive/women-in-the-labor-force-a-databook-2015.pdf. [Accessed March 1, 2017].

[7] J.E. Jacobs, "Twenty-five years of research on gender and ethnic differences in math and science career choices: What have we learned?," New Directions For Child And Adolescent Development, vol. 2005, no. 110, pp. 85-94, 2005.

[8] D. Cvencek, A. N. Meltzoff, and A. G. Greenwald, "Math-gender stereotypes in elementary school children," Child Development, vol. 82, no. 3, pp. 766-779, 2011.

[9] M. Steffens and P. Jelenec, "Separating implicit gender stereotypes regarding math and language: Implicit ability stereotypes are self-serving for boys and men, but not for girls and women," Sex Roles, vol. 64, no. 5/6, pp. 324-335, 2011.

[10] A. Smeding, "Women in science, technology, engineering, and mathematics (STEM): An investigation of their implicit gender stereotypes and stereotypes' connectedness to math performance," Sex Roles, vol. 11, no. 12, pp. 617-629, 2012.

[11] T. Frontier and J. Rickabaugh, Five Levers to Improve Learning: How to Prioritize for Powerful Reults in Your School. Alexandria, Virginia: Association for Supervision and Curriculus Development, 2014. 
[12] C. Bieri Buschor, S. Berweger, A. Keck Frei, and C. Kappler, Majoring in STEM- What accounts for women's career decision making? A mixed methods study," Journal of Education Research, vol. 107, no. 3, pp. 167-176, 2014.

[13] M. Meyer, A. Cimpian, and S. Leslie, (2015). "Women are underrepresented in fields where success is believed to require brilliance," Frontiers in Psychology, vol. 6, pp. 1-12, 2015.

[14] J. McIlwee and J. G. Robinson, Women in engineering: Gender, power and workplace culture. Albany, NY: State University of New York Press, 1992.

[15] Ohio State University, "Women in Engineering," osu.edu, 2017. [Online]. Available: https://wie.osu.edu/wie-rise. [Accessed March 7, 2017].

[16] Akron University, "Women in Engineering programs," uakron.edu, 2017. [Online]. Available: http://www.uakron.edu/engineering/beyond-the-classroom/women-inengineering/outreach-camps.dot. [Accessed March 7, 2017].

[17] Arizona State University, "Fulton Summer Academy," asu.edu, 2017. [Online]. Available: https://outreach.engineering.asu.edu/summer-programs/. [Accessed May 19, 2017].

[18] Purdue University, "Youth Programs," purdue.edu, 2017. [Online]. Available: http://www.purdue.edu/purdue/about/youthPrograms.html. [Accessed March 7, 2017].

[19] N. Bachman, P. J. Bischoff, H. Gallagher, S. Labroo, and J. C. Schaumloffel, "PR²EPS: Preparation, recruitment, retention and excellence in the physical sciences. A report on the 2004, 2005 and 2006 summer camps," Journal of STEM Education: Innovations \& Research, vol. 9, no. 1, 2008.

[20] L. Bottomley, J. P. Lavelle, S. B. D'Amico, and L. D. LaPorte, (2015). "Engineering summer programs: A strategic model," In Proc. 122nd ASEE Annual Conference \& Exposition, 2015, pp. 1-22.

[21] A. Bandura, "Guide for Constructing Self Efficacy Scales," in Self Efficacy Beliefs of Adolescents, T.C. Urdan and F. Pajares, Eds. Charlotte, North Carolina: Information Age Publishing, 2006, pp 307-337.

[22] Assessing Women and Men in Engineering (AWE) Project, (2008). "Pre-college annual self-efficacy survey," engr.psu.edu, 2008. [Online] Available: https://www.engr.psu.edu/awe/misc/about.aspx. [Accessed May 17, 2017].

[23] National Academy of Engineering, Changing the conversation: Messages for improving public understanding of engineering, Washington, D.C.: National Academy of Engineering, 2008. 
[24] J. Shull and M. Weiner, "Thinking inside the box: self-efficacy of women in engineering," International Journal of Engineering Education, vol. 18, no. 4, pp. 438446, 2002.

[25] S. R. Adams, "Stereotype threat," in Salem Press Encyclopedia, Ipswitch, MA: Salem Press, 2013. [Online] Available:

http://search.ebscohost.com/login.aspx?direct=true $\& \mathrm{db}=\mathrm{ers} \& \mathrm{AN}=89677640 \&$ site $=$ edslive. [Accessed Feb. 3, 2018].

[26] T. Schmader, M. Johns, and M. Barquissau, "The costs of accepting gender differences: the role of stereotype endorsement in women's experience in the math domain," Sex Roles, vol. 50, no. 11/12, pp. 835-850, 2004.

[27] B. K. Garner, Getting to Got it. Alexandria, VA: Association for Supervision and Curriculum Development, 2007.

[28] S. Han, R. Rosli, M. M. Capraro, and M. R. Capraro, (2016). "The effect of science, technology, engineering and mathematics (STEM) project based learning (PBL) on students' achievement in four mathematics topics," Journal of Turkish Science Education, vol. 13, pp. 3-29, 2016.

[29] J. Kretchmar, "Problem-based learning," Research Starters: Education, Online Edition, 2013.

[30] S. C. McLoone, B. J. Lawlor, and A. R. Meehan, "The implementation and evaluation of a project-oriented problem-based learning module in a first year engineering programme," Journal of Problem Based Learning in Higher Education, vol. 4, no. 1, pp. 71-80, 2016.

[31] Keen Engineering Unleashed, (2017). "Mindset Matters," engineeringunleashed.com, Jan. 2017. [Online]. Available https://engineeringunleashed.com/Mindset-Matters.aspx. [Accessed March 21, 2017].

[32] W. A. Wulf, (2002). "The importance of diversity in engineering," in Diversity in Engineering: Managing the Workforce of the Future, National Academies Press, Washington, DC: National Academies Press, pp 8-14. 


\section{Appendix A}

Participant Survey

1. How much do you enjoy solving problems?
a. I very much enjoy solving problems.
b. I somewhat enjoy solving problems.
c. I neither enjoy nor dislike solving problems.
d. I somewhat dislike solving problems.
e. I very much dislike solving problems.

2. When confronted with a challenge:
a. I continue to work hard to move past it.
b. I continue to work but feel somewhat set back.
c. I continue to work but feel very set back.
d. I feel very set back and don't work as much.
e. I give up entirely.

3. How often do you raise your hand to answer questions during class?
a. I raise my hand for every question.
b. I raise my hand for most questions.
c. I raise my hand for few questions.
d. I raise my hand for no questions.

4. How confident are you in your math and science skills?
a. I am very confident in my math and science skills.
b. I am somewhat confident in my math and science skills.
c. I am neither confident nor unconfident in my math and science skills.
d. I am somewhat unconfident in my math and science skills.
e. I am very unconfident in my math and science skills.

5. How confident are you in your ability to complete math and science classes?
a. I am very confident in my ability to complete math and science classes.
b. I am somewhat confident in my ability to complete math and science classes.
c. I am neither confident nor unconfident in my ability to complete math and science classes.
d. I am somewhat unconfident in my ability to complete math and science classes.
e. I am very unconfident in my ability to complete math and science classes.

6. What is your favorite subject in school? (circle all that apply)
a. Science
b. Math
c. Social Studies
d. English
e. Art
f. Health and Physical Education
g. Other: 
7. Pick the statement below that best describes what engineering means to you.

a. Engineering improves our lives by creating new solutions that connect science to life.

b. Engineering means being brilliant and doing well in math and science.

c. Engineering leads to good jobs and making money.

d. None of these describe what engineering means to me.

8. How interested are you in engineering as a college major?

a. I am very interested in engineering.

b. I am somewhat interested in engineering.

c. I am neither interested nor uninterested in engineering.

d. I am somewhat uninterested.

e. I am very uninterested in engineering.

9. How likely are you to continue with engineering in future education?

a. I am very likely to continue pursuing engineering.

b. I am somewhat likely to continue pursuing engineering

c. I am neither likely nor unlikely to continue pursuing engineering.

d. I am somewhat unlikely to continue pursuing engineering.

e. I am very unlikely to continue pursuing engineering.

10. How confident are you that you have what it takes to be an engineer?

a. I am very confident that I have what it takes to be an engineer.

b. I am somewhat confident that I have what it takes to be an engineer.

c. I am neither confident nor unconfident that I have what it takes to be an engineer.

d. I am somewhat unconfident that I have what it takes to be an engineer.

e. I am very unconfident that I have what it takes to be an engineer.

Question 11 varied between the pre-camp and post-camp survey iteration. On the pre-camp survey, participants were asked what they hoped to get out of their camp experience. On the post-camp survey, participants were asked what activity they found the most interesting and exciting. 